\title{
The mTOR Kinase Inhibitor CZ415 Inhibits Human Papillary Thyroid Carcinoma Cell Growth
}

\author{
Xiaobin Li Zongze Li Yimin Song Wenjing Liu Ziwen Liu \\ Department of General Surgery, Peking Union Medical College Hospital, Chinese Academy of Medical \\ Sciences \& Peking Union Medical College, Beijing, China
}

\section{Key Words}

Papillary thyroid carcinoma (PTC) • MTOR • CZ415 • Autophagy

\begin{abstract}
Background/Aim: Mammalian target of rapamycin (mTOR) plays an important role in papillary thyroid carcinoma (PTC) cell progression. CZ415 is a novel, highly-efficient and specific mTOR kinase inhibitor. The current study tested the potential anti-tumor activity of CZ415 in human PTC cells. Methods: The established (TPC-1 cell line) and primary human PTC cells were treated with CZ415. Cell survival and growth were tested by Cell Counting Kit- 8 assay and BrdU ELISA assay, respectively. Cell apoptosis was tested by caspase-3/-9 activity assay, Hoechst-33342 staining assay and single-stranded DNA ELISA assay. Cell cycle progression was tested by propidium iodide-FACS assay. The mTOR signaling was tested by Western blotting assay and co-immunoprecipitation assay. The mouse xenograft tumor model was applied to study the effect of CZ415 in vivo. Results: In cultured human PTC cells, treatment with CZ415 at nM concentrations significantly inhibited cell survival and growth. CZ415 induced apoptosis activation and cell cycle arrest in human PTC cells. CZ415 disrupted assembling of mTORC1 (mTOR-Raptor association) and mTORC2 (mTOR-Rictor-G $\beta$ L association) in TPC-1 cells, which led to de-phosphorylation of the mTORC1 substrates (S6K1 and 4E-BP1) and the mTORC2 substrate AKT (Ser-473). Further studies show that the autophagy inhibitor 3-methyladenine (3-MA) or Beclin-1 shRNA aggravated CZ415-induced cytotoxicity against PTC cells. In vivo, CZ415 oral administration inhibited TPC-1 xenograft tumor growth in mice. Conclusion: Our results show that mTOR blockage by CZ415 inhibits PTC cell growth in vitro and in vivo.
\end{abstract}

\section{Introduction}

Thyroid cancer is a main health threat in China [1,2] and around the world [3, 4]. Its incidence has been tripled in the past decades [3-5]. Over three-quarter of thyroid cancers are papillary thyroid carcinomas (PTC) [1,2]. PTC's pathogenesis is still not fully understood $[1,2]$. Existing studies suggest that radiation and genetic susceptibility contribute to the X. Li and Z. Li contributed equally to this work. 


\section{Cellular Physiology Cell Physiol Biochem 2018;46:579-590 \begin{tabular}{ll|l} 
DOI: 10.1159/000488625 & $\begin{array}{l}\text { O } 2018 \text { The Author(s). Published by S. Karger AG, Basel } \\
\text { www.karger.com/cpb }\end{array}$
\end{tabular}}

Li et al.: CZ415 Inhibits Human Papillary Thyroid Carcinoma Cell Growth

initiation and progression of PTC [6-11]. The molecularly-targeted therapy is important for better and efficient treatment of PTC [8-13].

Over-activation of mammalian target of rapamycin (mTOR) is important for a number of pro-cancerous cell behaviors, including cell survival, proliferation and cell cycle progression, as well as apoptosis escape, chemo-resistance and angiogenesis [14]. Dysregulation of mTOR signaling is often detected in PTC and other thyroid cancers [15-18]. Furthermore, mTOR inhibition can inhibit PTC cell progression [15-18]. mTOR has two multi-protein complexes, mTOR complex 1 (mTORC1) and mTOR complex 2 (mTORC2). mTORC1 is composed of mTOR, Raptor and PRAS40, which phosphorylates the downstream substrate proteins, p70S6K1 (S6K1) and eIF4E-binding protein 1 (4E-BP1) [14]. The function of mTORC1 can be inhibited by rapamycin and its analogs, RAD001 and CCI-779. mTORC2 is mainly composed of mTOR, Rictor, Sin1 and GBL (also known as mLST8) [14]. mTORC2 can function as the upstream kinase of AKT (at Ser-473) and several other AGC kinases [14]. The activity of mTORC2 can't be directly inhibited by rapamycin, yet prolonged rapamycin treatment could also inhibit mTORC2 [19].

Recent studies have developed CZ415 as a novel mTOR kinase inhibitor [20-22]. It can interfere with the mTOR kinase domain to block mTORC1 and mTORC2 activation simultaneously [20-22]. Our study tested its activity in human PTC cells.

\section{Materials and Methods}

Chemicals and reagents

CZ415 was a gift from Dr. Wang [20]. All the antibodies were provided by Cell Signaling Tech (Shanghai, China). The autophagy inhibitor 3-methyladenine (3-MA) was purchased from Sigma-Aldrich (Shanghai, China). The cell culture reagents were provided by Hyclone (Shanghai, China). Puromycin was purchased from Biyuntian (Wuxi, China).

Cell culture

TPC-1 human thyroid cancer cell line was purchased from the Cell Bank of Shanghai Institute of Biological Science (Shanghai, China). Cells were propagated in Dulbecco's Modified Eagle Medium (DMEM) with 10\% fetal bovine serum (FBS). Tumor tissues from a total of four written-informed primary PTC patients (47/54/52/62 years old, all male) were obtained at the time of thyroidectomy. Tumor tissues and surrounding normal thyroid tissues were separated carefully. The tissues were minced, followed by digestion as described [23]. The resulting primary cells were filtered under a $50-\mu$ mylon cell strainer. Primary cells were maintained in described complete DMEM/F12 medium [23]. The fibroblasts and blood vessels were removed carefully [23]. A total of four lines of primary PTC cells ("Line1/2/3/4") and two lines of thyroid follicular epithelial cells ("Epi-1/2") were established. Thyroid cancer and epithelial cell markers were validated as described [23]. The protocols using human samples/cells were in accordance with the principles expressed in the Declaration of Helsinki, and were approved by the Institutional Review Board (IRB) and Ethics Board of all authors' institutions.

\section{BrdU ELISA assay}

Cells were plated onto ninety-six-well tissue culture plates (Corning, Shanghai, China). Cells with the applied CZ415 treatment were incubated with BrdU $(10 \mu \mathrm{M})$. Afterwards, BrdU incorporation was determined via a commercial available ELISA kit (Cell Signaling Tech). BrdU ELISA optic density (OD) at 405 nm was recorded.

CCK-8 assay.

Cell Counting Kit (CCK-8) (Beyotime, Shanghai, China) assay was performed to test cell viability. Briefly, cells were plated onto ninety six-well tissue culture plates at 1000 cells per well. Following the treatment, $10 \mu \mathrm{L}$ of CCK-8 reagent was added to each well. After one hour, CCK-8's OD at $450 \mathrm{~nm}$ was measured.

Colony formation assay.

Cells were seeded onto six-well tissue culture plates at 500 cells per well, which were treated with/out CZ415 every two days for a total of ten days. Afterwards, colonies were washed twice using PBS, fixed with methanol/acetic acid, and stained in $1 \%$ crystal violet. The number of colonies was counted. 


\section{Cellular Physiology Cell Physiol Biochem 2018;46:579-590 \begin{tabular}{ll|l} 
DOI: 10.1159/000488625 & (0 2018 The Author(s). Published by S. Karger AG, Basel \\
www.karger.com/cpb
\end{tabular}}

Li et al.: CZ415 Inhibits Human Papillary Thyroid Carcinoma Cell Growth

Cell cycle assay

The cell cycle distribution was assessed by the propidium iodide (PI, Invitrogen, Shanghai, China) flow cytometry assay. Cells were plated onto six-well tissue culture plates at $3 \times 10^{5}$ per well. Following the applied treatment, cells were washed, harvested and fixed. Cells were then incubated with DNase-free RNase and stained with PI, and were tested via a FACSCalilur (BD Biosciences, Shanghai, China).

\section{Caspase-3/-9 activity assay}

After the following CZ415 treatment, $20 \mu \mathrm{g}$ protein lysates per treatment were incubated with the caspase assay buffer (Biyuntian, Wuxi, China) together with the caspase-3 substrate Ac-DEVD-pNA (Biyuntian) or the caspase- 9 substrate Ac-LEHD-pNA (Biyuntian) for $45 \mathrm{~min}$. The release of pNA, reflecting the relative caspase activity, was detected at $450 \mathrm{~nm}$.

\section{Apoptosis assay}

Following the treatment, cells were stained with nuclei dye Hoechst-33342 (Sigma). Normal nuclei show faint delicate chromatin staining, nuclei showing intensified Hoechst-33342 condensation/brightness (early apoptotic cells) or fragmentation (late apoptotic cells) were labeled as apoptotic cells.

\section{ssDNA ELISA assay}

The production of denatured single-stranded DNA (ssDNA) is an established marker of cell apoptosis, which was examined by a nucleosomal monoclonal antibody using the ELISA format as described previously [24]. The ssDNA ELISA OD value at $450 \mathrm{~nm}$ was tested.

\section{Western blotting assay}

The quantified lysate proteins ( $40 \mu \mathrm{g}$ per treatment of each lane) were separated by $10-12 \%$ of SDSPAGE gels, and were electrophoretically transferred to the PVDF membrane (Millipore, Shanghai, China). The blot was blocked (in 10\% milk), followed by probing with applied primary and secondary antibodies. Enhanced chemiluminescence (ECL) reagents were used to analyze targeted protein expression, and $\beta$-Tubulin ("Tubulin") was always tested as the protein loading control.

mTOR co-Immunoprecipitation (Co-IP)

The protein lysates (1000 $\mu \mathrm{g}$ per treatment) were pre-cleared. The pre-cleared lysate samples were incubated with anti-mTOR antibody (Cell Signaling Tech) overnight. Protein G Sepharose (30 $\mu \mathrm{L}$ per treatment, Sigma) was then added again to the lysates. mTOR complexes were then washed and subjected to Western blotting assay.

ShRNA

The lentiviral particles with Beclin-1 shRNA (sc-29797-V), Rictor shRNA (sc-61478-V) as well as the scramble control shRNA were purchased from Santa Cruz Biotech (Shanghai, China). The shRNA-containing lentivirus was added to cultured TPC-1 cells for 12 hours. After infection, puromycin $(3.0 \mu \mathrm{g} / \mathrm{mL})$ was added to select stable cells if necessary. Knockdown of targeted protein (Beclin-1 or Rictor) was confirmed by the Western blotting assay.

\section{In vivo tumorigenesis assay}

The female severe combined immunodeficient (SCID) mice (4-5 weeks of age, 17.0-18.0g of weight) were purchased from the Experimental Animal Center of Suzhou University (Suzhou, China). TPC-1 cells $\left(5 \times 10^{6}\right.$ cells of each mouse) were injected to the dorsal flank of the SCID mice. Within three weeks, the volume of each tumor was around $100 \mathrm{~mm}^{3}$, and the tumor-bearing mice were randomly assigned into two groups (10 mice per group), receiving CZ415 or the vehicle control. Tumor size was measured every 6 days. The tumor volume $=\left(D \times d^{2}\right) / 2$ was applied to evaluate tumor volume, where " $D$ " is the longest diameter and " $\mathrm{d}$ " is the shortest diameter. All experiments on animal were performed according to the Animal Experimental Ethics Committee of authors' institution.

\section{Statistics}

The results were expressed as the mean \pm standard deviation (SD). Statistical significance $(p<0.05)$ was evaluated by one-way ANOVA followed by Bonferroni post hoc test (SPSS 18.0, Chicago, IL). 


\section{Results}

CZ415 inhibits human papillary thyroid carcinoma cell survival and growth

The structure and molecular weight of CZ415 were presented in Fig. 1A. TPC-1 is an established human PTC cell line $[25,26]$. TPC-1 cells were cultured in FBS-containing complete medium, and were treated with different concentrations (10-1000 nM) of CZ415. The cell growth curve results in Fig. 1B show that treatment with CZ415 at 100/1000 nM significantly inhibited TPC- 1 cell growth. The anti-growth activity of CZ415 was dosedependent, and $10 \mathrm{nM}$ of CZ415 was ineffective (Fig. 1B). CZ415 (100/1000 nM) also inhibited BrdU incorporation in TPC-1 cells (Fig. 1C). Cell Counting Kit-8 (CCK-8) assay was applied to test TPC- 1 cell viability. The results demonstrate that CZ415 dose-dependently decreased TPC-1 cell CCK-8 viability optic density ("OD", Fig. 1D). The clonogenicity assay results show that the number of viable TPC-1 colonies was significantly decreased following 100/1000 nM of CZ415 treatment (Fig. 1E).

Then we tested the potential effect of the novel mTOR kinase inhibitor [20-22] on the primary human PTC cells. Four lines of primary human PTC cells were established, and named as "Line1/2/3/4". Line1 and Line2 primary human PTC cells were PTEN deficient with high basal AKT activation (Fig. 1F). Line3 and Line 4 cells were PTEN positive with weak AKT activation (Fig. 1F). Treatment with CZ415 (1000 nM) inhibited viability (CCK-8 OD) of all four lines of primary human PTC cells (Fig. 1G). PTEN-depleted cells (Line1 and Line2) were more sensitive to CZ415 (Fig. 1G).

In order to test the activity of CZ415 in the non-cancerous cells, two lines of primary human thyroid epithelial cells were cultured, named as "Epi-1" and "Epi-2" (See Methods). Notably, treatment with CZ415 at a high concentration (1000 nM) failed to inhibit the viability of these epithelial cells (Fig. 1H). These results demonstrate an unique response of this mTOR kinase inhibitor against cancerous cells.

CZ415 induces apoptosis activation in human papillary thyroid carcinoma cells

Apoptosis activation can be a main reason of growth inhibition and cytotoxicity in cancer cells $[27,28]$. Western blotting assay results in Fig. 2A show that CZ415 (100/1000 nM) treatment induced cleavage of both caspase- 3 and caspase- 9 in TPC- 1 cells. The activity of caspase-3 and caspase- 9 were increased significantly in CZ415 (100/1000 nM)-treated cells (Fig. 2B). Cleaved-caspase-3 and cleaved-caspase- 9 will travel into cell nuclei, causing DNA cleavage. The results show that the content of single strand DNA ("SsDNA") was increased after CZ415 (100/1000 nM) treatment (Fig. 2C). Hoechst-33342 staining assay was also performed to test cell apoptosis. The non-apoptotic normal nuclei showed faint delicate 
chromatin staining, the nuclei with increased Hoechst33342 condensation/brightness (early apoptotic cells) or fragmentation (late apoptotic cells) were labeled as apoptotic nuclei. CZ415 (100/1000 nM) significantly increased the percentage of TPC-1 cells with apoptotic nuclei (Fig. 2D). These results suggest that CZ415 induced apoptosis activation in TPC-1 cells.

Hoechst-33342 apoptotic nuclei staining assay results in Fig. 2E show that CZ415 (1000 nM, 48 hours) induced apoptosis activation of all four lines of primary human PTC cells. Its pro-apoptotic activity is more significant in two lines of PTEN-depleted human PTC cells ("Line1/2") (Fig. 2E). Conversely, CZ415 failed to induce significant apoptosis in primary thyroid epithelial cells (Fig. 2F).

CZ415 disrupts PTC cell cycle progression

We also analyzed cell cycle distribution in CZ415treated PTC cells. Quantified results in Fig. 3A confirmed that treatment with CZ415 (1000 nM, 24 hours) disrupted TPC-1 cell cycle progression. Following the CZ415 treatment, G0-1 phase TPC-1 cells were increased, and the G2-M phase cells were decreased (Fig. 3A). These results suggest that CZ415 induced G1-S arrest in TPC1 cells. It has been previously shown that mTOR is required for the expression of several cell cycle-related proteins, including Cyclin D1 [29] and Cyclin E1 [30]. Here, our results show that Cyclin D1 and Cyclin E1 were downregulated by CZ415 (1000 nM, 12 hours) in TPC-1 cells (Fig. 3B-C).

\section{CZ415 blocks mTORC1 and mTORC2 activation in PTC cells}

mTOR is in two multiple protein complexes (mTORC1/2). The mTOR-Raptor complex ("mTORC1") can phosphorylate S6K1 and 4E-BP1. mTOR-Rictor-GßL complex ("mTORC2") phosphorylates AKT at Ser-473 [14]. The co-immunoprecipitation ("Co-IP") assay was performed to test the assembly of these two mTOR complexes. Results in Fig. 4A show that the mTOR-Raptor complex and mTOR-Rictor-GßL complex were disrupted by CZ415 (1000 nM, 2 hours) in TPC- 1 cells. Expression of mTOR complex proteins, including mTOR, Raptor, Rictor and GßL, were unchanged after CZ415 treatment (Fig. 4A, "INPUT"). Treatment with 


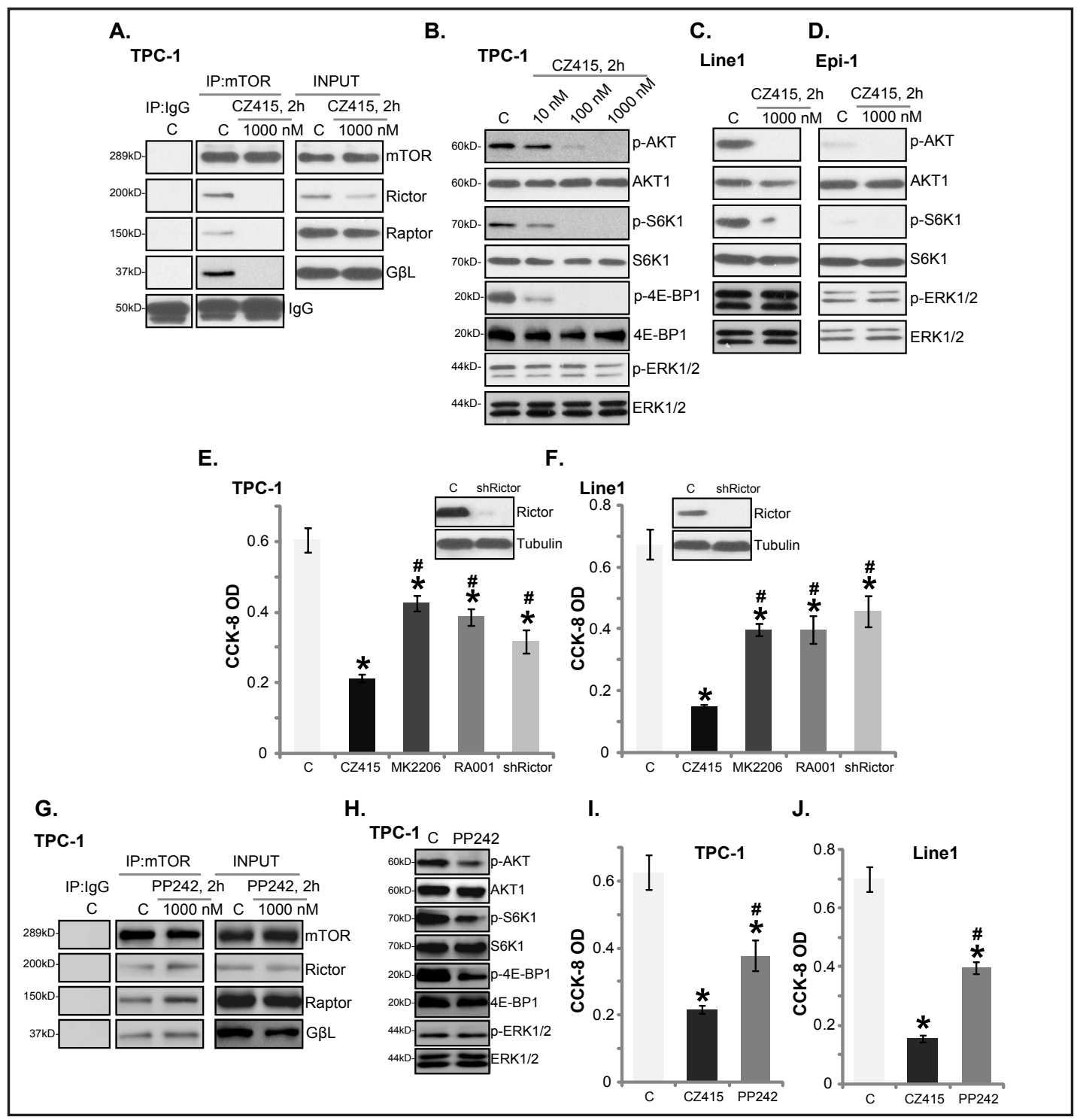

Fig. 4. CZ415 blocks mTORC1 and mTORC2 activation in PTC cells. TPC-1 cells (A, B, G and H), the primary PTC cells ("Line1", C) or the primary human thyroid epithelial cells ("Epi-1", D) were treated with CZ415 (1000 nM) or PP242 (1000 nM), cells were cultured for 2 hours; the mTOR-Raptor association and the mTOR-Rictor-GßL association were tested by co-immunoprecipitation ("Co-IP") assay (A and G, left panel); Expression of the listed proteins were shown [A and G, right panel ("INPUT"), B-D and H]; TPC-1 cells (E and I) or the primary PTC cells ("Line1", F and J) were treated with CZ415 (1000 nM), P242 (1000 nM), MK-2206 (1000 nM), RAD001 (1000 nM), or infected with Rictor shRNA ("shRictor") lentivirus; Cells were further cultured for 72 hours, and cell viability was tested by CCK-8 assay (E, F, I and J). Rictor expression was also shown (E and F, the upper panel). Data were presented as mean \pm standard deviation (SD, $n=5$ ). *p $<0.05$ vs. "C" group. ${ }^{\#}$ p $<0.05$ vs. "CZ415" only group. The experiments were repeated three times, and similar results were obtained.

CZ415 almost completely blocked phosphorylation of mTORC1 substrates S6K1 (Thr-389) and 4E-BP1 (Ser-65), as well as the mTORC2 substrate AKT (Ser-473) (Fig. 4B). Total S6K1, 4E-BP1 and AKT1 were unchanged (Fig. 4B). Furthermore, the activation or phosphorylation of ERK1/2 was also not affected by CZ415 (Fig. 4B).

Western blotting assay results in Fig. 4C show that CZ415 treatment blocked phosphorylation of S6K1 (Thr-389) and AKT (Ser-473) in the primary human PTC cells ("Line-1"). Ad- 
ditionally, the basal phosphorylation of S6K1 (Thr389) and AKT (Ser-473) were extremely low in the primary thyroid epithelial cells ("Epi-1") (Fig. 4D). This might explain why the epithelial cells were not killed by the mTOR kinase inhibitor (Fig. 1 and 2). ERK1/2 phosphorylation and expression were unchanged after CZ415 treatment (Fig. 4C and D). These results demonstrate that CZ415 blocked mTORC1 and mTORC2 activation in human PTC cells.

We compared CZ415 activity with other known AKT-mTOR inhibitors, including the AKT specific inhibitor MK-2206 [31-33] and the mTORC1 inhibitor RAD001 [34, 35]. Results in Fig. 4E show that CZ415 was more potent than MK-2206 and RAD001 in inhibiting TPC-1 cell survival. Meanwhile, CZ415induced cytotoxicity was more significant than mTORC2 inhibition by Rictor shRNA (Fig. 4E). The similar results were also observed in the primary human PTC cells ("Line1 "), and CZ415's cytotoxicity was more robust than MK-2206, RAD001 and Rictor shRNA (Fig. 4F). Thus, mTORC1/2 dual inhibition by CZ415 is more efficient in killing PTC cells than blockage of either mTORC1 or MTORC2.

Importantly, treatment with PP242, another known mTOR kinase inhibitor [36], had no significant effect on the assembling of mTORC1 and mTORC2 in TPC-1 cells (Fig. 4G). The expression of mTOR complex proteins, mTOR, Raptor, Rictor and GßL, were not affected by PP242 (Fig. 4G, "Input"). PP242 treatment only resulted in partial

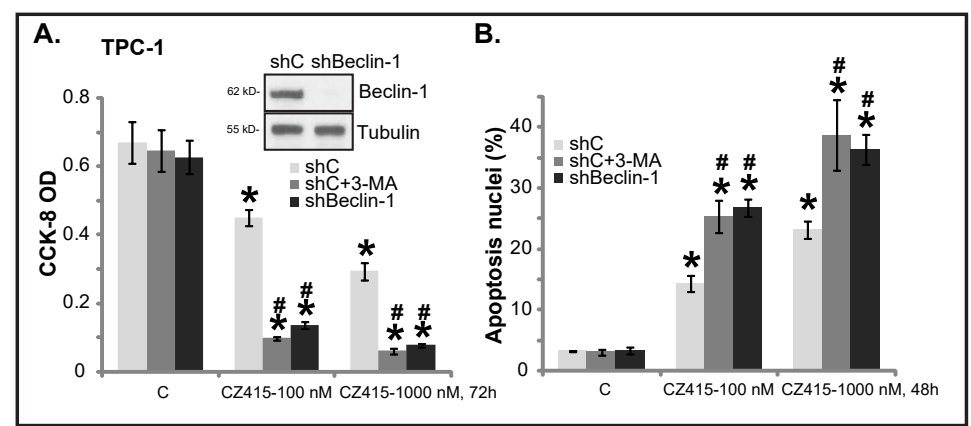

Fig. 5. Autophagy inhibition sensitizes CZ415-induced cytotoxicity in PTC cells. TPC-1 cells with Beclin shRNA ("shBeclin-1") or scramble control shRNA ("shC") were treated with/out CZ415 (100 and 1000 $\mathrm{nM}$ ), cells were cultured in the conditional medium for applied time; Beclin-1 expression was tested by Western blotting assay (A, the upper panel); Cell survival and apoptosis were tested by CCK-8 assay (A, the lower panel) and Hoechst-33342 staining assay (B), respectively. Data were presented as mean \pm standard deviation (SD, $n=5$ ). * $p<0.05$ vs. "C" group. * p<0.05 vs. "shC" group. The experiments were repeated three times, and similar results were obtained.

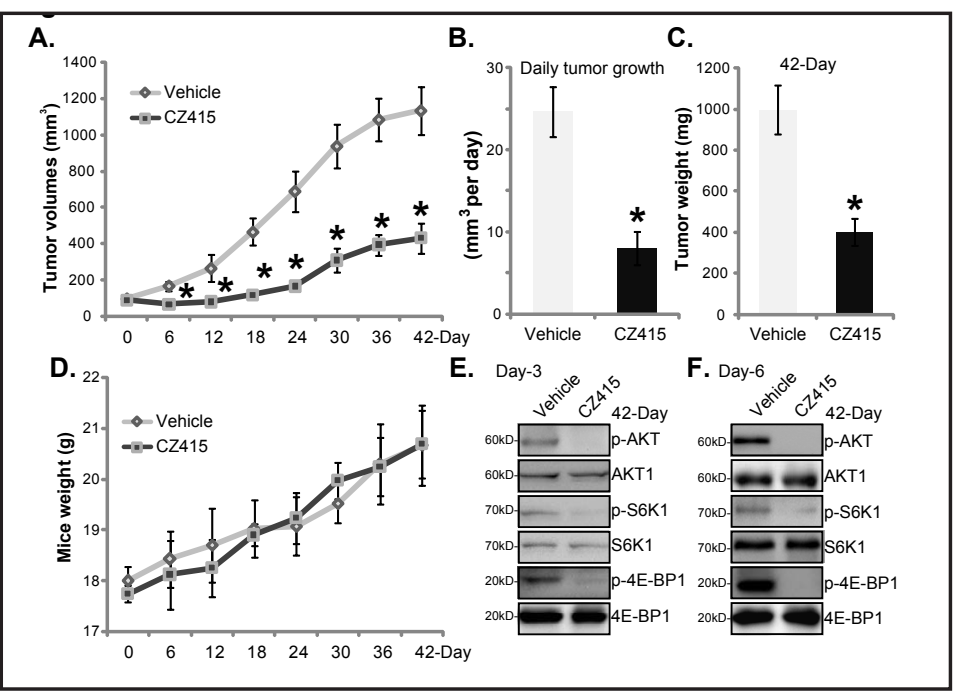

Fig. 6. CZ415 inhibits TPC-1 tumor growth in mice. TPC-1 tumor-bearing SCID mice were administrated with CZ415 (20 mg/kg body weight, gavage, daily for 24 days) or vehicle control (Saline), tumor volumes (A, in $\mathrm{mm}^{3}$ ) and mice body weights (D, in gram) were recorded every 6 days for a total of 42 days; Estimated daily tumor growth (in $\mathrm{mm}^{3}$ per day) was calculated as described (B); At day-42, each single tumor of the two groups was isolated and weighted (C). Data were presented as mean \pm standard deviation (SD, n=10). At Day-3 (E) and Day-6 (F), 2 hours after initial CZ415/Vehicle treatment, one tumor per group was isolated, the tumor tissues were lysed, and expression of listed proteins in tumor lysates were tested by the Western blotting assay.* $p<0.05$ vs. "Vehicle" group.

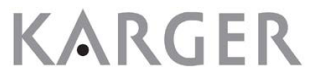


inhibition of phosphorylation of AKT, S6K1 and 4E-BP1 in TPC-1 cells (Fig. 4H). ERK1/2 activation, as expected, was not affected by PP242 (Fig. 4H). Consequently, PP242 was less effective than CZ415 in inhibiting the viability of PTC-1 cells (Fig. 4I) and the primary human PTC cells ("Line-1") (Fig. 4J).

\section{Autophagy inhibition sensitizes CZ415-induced cytotoxicity in PTC cells}

It has been shown that mTOR blockage can induce feedback autophagy activation, which might serve as a pro-survival factor to inhibit cancer cell death [37-39]. To block autophagy, pharmacological and genetic stragies were utilized. Three-methyladenine (3-MA) is a well-known autophagy inhibitor [40]. Beclin-1 is a key protein of autophagy initiation and progression $[41,42]$. Beclin-1 knockdown has been utilized to block autophagy in cancer cells [43]. The applied lentiviral Beclin-1 shRNA induced efficient knockdown of Beclin-1 in TPC-1 cells (Fig. 5A, the upper panel). Significantly, CZ415 (100/1000 nM)-induced TPC-1 cell viability reduction (Fig. 5A, the lower panel) and apoptosis activation (Fig. 5B) were potentiated by 3-MA and Beclin-1 shRNA. These results imply that autophagy inhibition could increase CZ415's sensitivity, and autophagy could be a key resistance factor for CZ415 treatment in PTC cells.

\section{CZ415 inhibits TPC-1 tumor growth in mice}

At last, the potential anti-tumor activity of CZ415 in vivo was tested. TPC-1 cells were inoculated via s.c. injection to the severe combined immunodeficient (SCID) mice. When the volume of each tumor was around $100 \mathrm{~mm}^{3}$, tumor-bearing mice were randomly separated into two groups, which were treated with CZ415 or the vehicle control ( $\mathrm{n}=10$ for each group). Tumor growth curve results in Fig. 6A demonstrated that oral administration of CZ415 (20 $\mathrm{mg} / \mathrm{kg}$ body weight [22], daily for 24 days) significantly inhibited TPC-1 xenograft tumor growth in mice. The daily tumor growth was calculated using the formula: [Tumor volume at day-42 $\left(\mathrm{mm}^{3}\right)$-Tumor volume at day-0 $\left.\left(\mathrm{mm}^{3}\right)\right] / 42$. Results in Fig. 6B show that estimated daily tumor growth was $24.70 \pm 3.05 \mathrm{~mm}^{3}$ per day in the vehicle mice, and it reduced to $8.09 \pm 2.01 \mathrm{~mm}^{3}$ per day after CZ415 treatment (Fig. 6B). At day-42, tumors of each group were isolated and weighted, and CZ415-treated tumors weighted dramatically lower than the vehicle control tumors (Fig. 6C). The mice body weight was not significantly different between the two groups (Fig. 6D).

At Day-3 and Day-6, two hours after CZ415/Vehicle treatment, one tumor per group was isolated, the tumor tissues were lysed for mTOR signaling analysis. When compared to the vehicle control tumors, results show that phosphorylation of AKT, S6K1 and 4E-BP1 were largely inhibited in the tumor tissues after CZ415 treatment (Fig. 6E and F). These results suggest that CZ415 possibly also blocks mTORC1 and mTORC2 activation in vivo. Collectively, our results show that CZ415 could inhibit TPC-1 xenograft tumor growth in vivo.

\section{Discussion}

The traditional mTORC1 inhibitors, i.e. rapamycin and its analogs ("rapalogs"), have displayed promising anti-tumor activity $[44,45]$. Whereas, the application of these inhibitors had several drawbacks $[44,45]$. First, rapalogs bind to FKBP12, leading to only partial inhibition of mTORC1 $[44,45]$. Second, these mTORC1 inhibitor can provoke feedback activation of multiple key oncogenic pathways, including ERK and AKT cascades [46]. Third, rapalogs have direct inhibition on mTORC2. In fact, rapamycin treatment could provoke AKT activation via the IRS-1-mediated feedback pathway [47, 48]. Fourth, the clinical administration of these mTORC1 inhibitor are usually limited due to poor solubility [44, 45]. Due to these limitations, mTOR kinase inhibitors, also known as the "second generation of mTOR inhibitors", were recently developed $[44,45]$.

CZ415 is a novel, highly-efficient and specific mTOR kinase inhibitor [20-22]. It displayed an extremely superior $\mathrm{K}_{\mathrm{d}}$ (nM ranges) and applicable pharmacokinetic/pharmacodynamic 
properties $[22,49]$. In the current study, our results show that CZ415 disrupted the assembling of both mTORC1 (mTOR-Raptor association) and mTORC2 (mTOR-Rictor$\mathrm{G} \beta \mathrm{L}$ ), causing de-phosphorylation of the mTORC1 substrate S6K1 and 4E-BP1 as well as the mTORC2 substrate AKT (Ser-473). CZ415 had no significant effect on ERK activation in human PTC cells. Treatment with CZ415 at nM concentrations significantly inhibited human TPC cell survival and growth, and also induced apoptosis activation and disrupted cell cycle progression. Notably, CZ415's cytotoxicity was more potent than MK-2206, RAD001 and Rictor shRNA.

One interesting finding of our research was that CZ415 disrupted the assembling of both mTORC1 and mTORC2, which resulted in almost complete inhibition of mTORC1 and mTORC2 in human PTC cells. Whereas, the other known mTOR kinase inhibitor PP242 had no direct effect on mTORC1/2 assembling, and it only caused partial inhibition of mTORC1/2 in human PTC cells. Therefore, it is possible that CZ415 binding to mTOR may induce mTOR conformational change, which leads to the disassembling of both mTORC1 and mTORC2. These results can also explain the superior activity of CZ415 against human PTC cells.

In vivo, oral administration of CZ415 at a well-tolerated dose $(20 \mathrm{mg} / \mathrm{kg}$ body weight $)$ significantly suppressed TPC-1 tumor growth in mice. Importantly, CZ415 was non-cytotoxic to the non-cancerous thyroid epithelial cells, and the results of in vivo administration show that there were no apparent toxicities to the experimental mice. Therefore, the current preclinical study displayed a superior anti-tumor activity of CZ415 against human PTC cells.

Although sustained and profound autophagy could promote cell death ("autophagic cell death"), drug-induced feedback autophagy activation is mostly gentle and has pro-survival ability especially in cancer cells $[28,50,51]$. In the process of autophagy, cell degrades its own components via lysosomal machineries, which provides energy and nutrients for cell to survive [52]. mTOR is a key kinase regulating cell autophagy [53,54]. Activation of mTOR is shown to suppress cell autophagy through directly inhibiting Ulk1, which is the upstream kinase initiating cell autophagy [55]. mTOR blockage, on the other hand, could lead to feedback autophagy activation $[53,54]$. Indeed, a number of mTOR inhibitors were shown to active autophagy in cancer cells, which counteracted cell death [37-39, 56]. Conversely, autophagy inhibition can increase the sensitivity and the anti-cancer efficiency of mTOR inhibitors [37-39]. In the current study, our results show that the autophagy inhibitor 3-MA or Beclin-1 shRNA potentiated CZ415-induced cytotoxicity in PTC cells. Therefore, cell autophagy could also be a key resistance factor of CZ415 in PTC cells.

\section{Conclusion}

Together, our results demonstrate that mTOR blockage by CZ415 inhibits PTC cell growth in vitro and in vivo. CZ415 could be further studied as a promising anti-PTC agent.

\section{Acknowledgements}

This study was supported by Peking Union Medical College Hospital.

All the listed authors in the study carried out the experiments, participated in the design of the study and performed the statistical analysis, conceived of the study, and helped to draft the manuscript.

\section{Disclosure Statement}

The authors declare no Disclosure Statements. 


\section{Cellular Physiology Cell Physiol Biochem 2018;46:579-590

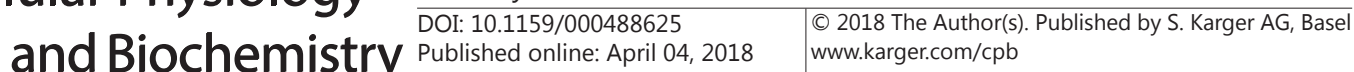

\section{References}

1 Xue S, Wang P, Liu J, Li R, Zhang L, Chen G: Prophylactic central lymph node dissection in cN0 patients with papillary thyroid carcinoma: A retrospective study in China. Asian J Surg 2016;39:131-136.

- Pinyi Z, Bin Z, Jianlong B, Yao L, Weifeng Z: Risk factors and clinical indication of metastasis to lymph nodes posterior to right recurrent laryngeal nerve in papillary thyroid carcinoma: a single-center study in China. Head Neck 2014;36:1335-1342.

-3 Siegel RL, Miller KD, Jemal A: Cancer Statistics, 2017. CA Cancer J Clin 2017;67:7-30.

4 Siegel RL, Miller KD, Jemal A: Cancer statistics, 2016. CA Cancer J Clin 2016;66:7-30.

-5 Zhang Q, Liu SZ, Guan YX, Chen QJ, Zhu QY: Meta-Analyses of Association Between BRAF(V600E) Mutation and Clinicopathological Features of Papillary Thyroid Carcinoma. Cell Physiol Biochem 2016;38:763-776.

6 Costa V, Esposito R, Pallante P, Ciccodicola A, Fusco A: The "next-generation" knowledge of papillary thyroid carcinoma. Cell Cycle 2015;14:2018-2021.

-7 Guo K, Wang Z: Risk factors influencing the recurrence of papillary thyroid carcinoma: a systematic review and meta-analysis. Int J Clin Exp Pathol 2014;7:5393-5403.

8 Fan C, Wang W, Jin J, Yu Z, Xin X: RASSF10 is Epigenetically Inactivated and Suppresses Cell Proliferation and Induces Cell Apoptosis by Activating the p53 Signalling Pathway in Papillary Thyroid Carcinoma Cancer. Cell Physiol Biochem 2017;41:1229-1239.

-9 Zhang Q, Liu SZ, Zhang Q, Guan YX, Chen QJ, Zhu QY: Meta-Analyses of Association Between BRAF(V600E) Mutation and Clinicopathological Features of Papillary Thyroid Carcinoma. Cell Physiol Biochem 2016;38:763-776.

10 Xu B, Shao Q, Xie K, Zhang Y, Dong T, Xia Y, Tang W: The Long Non-Coding RNA ENST00000537266 and ENST00000426615 Influence Papillary Thyroid Cancer Cell Proliferation and Motility. Cell Physiol Biochem 2016;38:368-378.

11 Qiu ZL, Shen CT, Sun ZK, Wei WJ, Zhang XY, Song HJ, Luo QY: Circulating Long Non-Coding RNAs Act as Biomarkers for Predicting 131I Uptake and Mortality in Papillary Thyroid Cancer Patients with Lung Metastases. Cell Physiol Biochem 2016;40:1377-1390.

-12 Vuong HG, Altibi AM, Abdelhamid AH, Ngoc PU, Quan VD, Tantawi MY, Elfil M, Vu TL, Elgebaly A, Oishi N, Nakazawa T, Hirayama K, Katoh R, Huy NT, Kondo T: The changing characteristics and molecular profiles of papillary thyroid carcinoma over time: a systematic review. Oncotarget 2017;8:10637-10649.

13 Santoro M, Melillo RM: Genetics: The genomic landscape of papillary thyroid carcinoma. Nat Rev Endocrinol 2015;11:133-134.

14 Sabatini DM: mTOR and cancer: insights into a complex relationship. Nat Rev Cancer 2006;6:729-734.

15 Minna E, Romeo P, Dugo M, De Cecco L, Todoerti K, Pilotti S, Perrone F, Seregni E, Agnelli L, Neri A, Greco A, Borrello MG: miR-451a is underexpressed and targets AKT/mTOR pathway in papillary thyroid carcinoma. Oncotarget 2016;7:12731-12747.

16 Minna E, Romeo P, De Cecco L, Dugo M, Cassinelli G, Pilotti S, Degl'Innocenti D, Lanzi C, Casalini P, Pierotti MA, Greco A, Borrello MG: miR-199a-3p displays tumor suppressor functions in papillary thyroid carcinoma. Oncotarget 2014;5:2513-2528.

17 Ahmed M, Hussain AR, Bavi P, Ahmed SO, Al Sobhi SS, Al-Dayel F, Uddin S, Al-Kuraya KS: High prevalence of mTOR complex activity can be targeted using Torin2 in papillary thyroid carcinoma. Carcinogenesis 2014;35:1564-1572.

-18 Faustino A, Couto JP, Populo H, Rocha AS, Pardal F, Cameselle-Teijeiro JM, Lopes JM, Sobrinho-Simoes M, Soares P: mTOR pathway overactivation in BRAF mutated papillary thyroid carcinoma. J Clin Endocrinol Metab 2012;97:E1139-1149.

19 Sarbassov DD, Ali SM, Sengupta S, Sheen JH, Hsu PP, Bagley AF, Markhard AL, Sabatini DM: Prolonged rapamycin treatment inhibits mTORC2 assembly and Akt/PKB. Mol Cell 2006;22:159-168.

20 Zhang W, Chen B, Zhang Y, Li K, Hao K, Jiang L, Wang Y, Mou X, Xu X, Wang Z: The anti-hepatocellular carcinoma cell activity by a novel mTOR kinase inhibitor CZ415. Biochem Biophys Res Commun 2017;487:494-499.

21 Yin G, Fan J, Zhou W, Ding Q, Zhang J, Wu X, Tang P, Zhou H, Wan B, Yin G: ERK inhibition sensitizes CZ415induced anti-osteosarcoma activity in vitro and in vivo. Oncotarget 2017;8:82027-82036. 


\section{Cellular Physiology Cell Physiol Biochem 2018;46:579-590 and Biochemistry Published $\begin{aligned} & \text { DOI: 10.1159/000488625 } \\ & \text { (c) } 2018 \text { The Author(s). Published by S. Karger AG, Basel } \\ & \text { www.karger.com/cpb }\end{aligned}$

22 Cansfield AD, Ladduwahetty T, Sunose M, Ellard K, Lynch R, Newton AL, Lewis A, Bennett G, Zinn N, Thomson DW, Ruger AJ, Feutrill JT, Rausch O, Watt AP, Bergamini G: CZ415, a Highly Selective mTOR Inhibitor Showing in vivo Efficacy in a Collagen Induced Arthritis Model. ACS Med Chem Lett 2016;7:768773.

-23 Duquette M, Sadow PM, Husain A, Sims JN, Antonello ZA, Fischer AH, Song C, Castellanos-Rizaldos E, Makrigiorgos GM, Kurebayashi J, Nose V, Van Hummelen P, Bronson RT, Vinco M, Giordano TJ, DiasSantagata D, Pandolfi PP, Nucera C: Metastasis-associated MCL1 and P16 copy number alterations dictate resistance to vemurafenib in a BRAFV600E patient-derived papillary thyroid carcinoma preclinical model. Oncotarget 2015;6:42445-42467.

24 Mao M, Liu Y, Gao X: Feedback autophagy activation as a key resistance factor of Ku-0060648 in colorectal cancer cells. Biochem Biophys Res Commun 2017;490:1244-1249.

25 Orlandella FM, Di Maro G, Ugolini C, Basolo F, Salvatore G: TWIST1/miR-584/TUSC2 pathway induces resistance to apoptosis in thyroid cancer cells. Oncotarget 2016;7:70575-70588.

26 Zhao JJ, Hao S, Wang LL, Hu CY, Zhang S, Guo LJ, Zhang G, Gao B, Jiang Y, Tian WG, Luo DL: Long non-coding RNA ANRIL promotes the invasion and metastasis of thyroid cancer cells through TGF-beta/Smad signaling pathway. Oncotarget 2016;7:57903-57918.

27 Ouyang L, Shi Z, Zhao S, Wang FT, Zhou TT, Liu B, Bao JK: Programmed cell death pathways in cancer: a review of apoptosis, autophagy and programmed necrosis. Cell Prolif 2012;45:487-498.

28 Chaabane W, User SD, El-Gazzah M, Jaksik R, Sajjadi E, Rzeszowska-Wolny J, Los MJ: Autophagy, apoptosis, mitoptosis and necrosis: interdependence between those pathways and effects on cancer. Arch Immunol Ther Exp (Warsz) 2013;61:43-58.

29 Averous J, Fonseca BD, Proud CG: Regulation of cyclin D1 expression by mTORC1 signaling requires eukaryotic initiation factor 4E-binding protein 1. Oncogene 2008;27:1106-1113.

-30 Zou ZQ, Zhang LN, Wang F, Bellenger J, Shen YZ, Zhang XH: The novel dual PI3K/mTOR inhibitor GDC-0941 synergizes with the MEK inhibitor U0126 in non-small cell lung cancer cells. Mol Med Rep 2012;5:503-508.

-31 Ji D, Zhang Z, Cheng L, Chang J, Wang S, Zheng B, Zheng R, Sun Z, Wang C, Zhang Z, Liu R, Zhang X, Liu X, Wang X, Li J: The combination of RAD001 and MK-2206 exerts synergistic cytotoxic effects against PTEN mutant gastric cancer cells: involvement of MAPK-dependent autophagic, but not apoptotic cell death pathway. PLoS One 2014;9:e85116.

-32 Yap TA, Yan L, Patnaik A, Fearen I, Olmos D, Papadopoulos K, Baird RD, Delgado L, Taylor A, Lupinacci L, Riisnaes R, Pope LL, Heaton SP, Thomas G, Garrett MD, Sullivan DM, de Bono JS, Tolcher AW: First-in-man clinical trial of the oral pan-AKT inhibitor MK-2206 in patients with advanced solid tumors. J Clin Oncol 2011;29:4688-4695.

33 Hirai H, Sootome H, Nakatsuru Y, Miyama K, Taguchi S, Tsujioka K, Ueno Y, Hatch H, Majumder PK, Pan BS, Kotani H: MK-2206, an allosteric Akt inhibitor, enhances antitumor efficacy by standard chemotherapeutic agents or molecular targeted drugs in vitro and in vivo. Mol Cancer Ther 2010;9:1956-1967.

-34 Awada A, Cardoso F, Fontaine C, Dirix L, De Greve J, Sotiriou C, Steinseifer J, Wouters C, Tanaka C, Zoellner U, Tang P, Piccart M: The oral mTOR inhibitor RAD001 (everolimus) in combination with letrozole in patients with advanced breast cancer: results of a phase I study with pharmacokinetics. Eur J Cancer 2008;44:8491.

35 Mabuchi S, Altomare DA, Cheung M, Zhang L, Poulikakos PI, Hensley HH, Schilder RJ, Ozols RF, Testa JR: RAD001 inhibits human ovarian cancer cell proliferation, enhances cisplatin-induced apoptosis, and prolongs survival in an ovarian cancer model. Clin Cancer Res 2007;13:4261-4270.

-36 Zeng Z, Shi YX, Tsao T, Qiu Y, Kornblau SM, Baggerly KA, Liu W, Jessen K, Liu Y, Kantarjian H, Rommel C, Fruman DA, Andreeff M, Konopleva M: Targeting of mTORC1/2 by the mTOR kinase inhibitor PP242 induces apoptosis in AML cells under conditions mimicking the bone marrow microenvironment. Blood 2012;120:2679-2689.

-37 Zhu YR, Zhou XZ, Zhu LQ, Yao C, Fang JF, Zhou F, Deng XW, Zhang YQ: The anti-cancer activity of the mTORC1/2 dual inhibitor XL388 in preclinical osteosarcoma models. Oncotarget 2016;7:49527-49538.

-38 Wei L, Chintala S, Ciamporcero E, Ramakrishnan S, Elbanna M, Wang J, Hu Q Glenn ST, Murakami M, Liu L, Gomez EC, Sun Y, Conroy J, Miles KM, Malathi K, Ramaiah S, Anbarasu A, Woloszynska-Read A, Johnson CS, Conroy J, Liu S, Morrison CD, Pili R: Genomic profiling is predictive of response to cisplatin treatment but not to PI3K inhibition in bladder cancer patient-derived xenografts. Oncotarget 2016;7:76374-76389. 


\section{Cellular Physiology Cell Physiol Biochem 2018;46:579-590 \begin{tabular}{l|l} 
DOI: 10.1159/000488625 & Ond Biochemistry 2018 The Author(s). Published by S. Karger AG, Basel \\
wwww.karger.com/cpb
\end{tabular}

39 Simioni C, Cani A, Martelli AM, Zauli G, Alameen AA, Ultimo S, Tabellini G, McCubrey JA, Capitani S, Neri LM: The novel dual PI3K/mTOR inhibitor NVP-BGT226 displays cytotoxic activity in both normoxic and hypoxic hepatocarcinoma cells. Oncotarget 2015;6:17147-17160.

40 Seglen PO, Gordon PB: 3-Methyladenine: specific inhibitor of autophagic/lysosomal protein degradation in isolated rat hepatocytes. Proc Natl Acad Sci U S A 1982;79:1889-1892.

41 Fu LL, Cheng Y, Liu B: Beclin-1: autophagic regulator and therapeutic target in cancer. Int J Biochem Cell Biol 2013;45:921-924.

42 Wu X, Feng X, Zhao X, Ma F, Liu N, Guo H, Li C, Du H, Zhang B: Role of Beclin-1-Mediated Autophagy in the Survival of Pediatric Leukemia Cells. Cell Physiol Biochem 2016;39:1827-1836.

-43 Zhang Q, Yang M, Qu Z, Zhou J, Jiang Q: Autophagy prevention sensitizes AKTi-1/2-induced antihepatocellular carcinoma cell activity in vitro and in vivo. Biochem Biophys Res Commun 2016;480:334340.

44 Zhou HY, Huang SL: Current development of the second generation of mTOR inhibitors as anticancer agents. Chin J Cancer 2012;31:8-18.

45 Vilar E, Perez-Garcia J, Tabernero J: Pushing the envelope in the mTOR pathway: the second generation of inhibitors. Mol Cancer Ther 2011;10:395-403.

46 Chen XG, Liu F, Song XF, Wang ZH, Dong ZQ, Hu ZQ, Lan RZ, Guan W, Zhou TG, Xu XM, Lei H, Ye ZQ, Peng EJ, Du LH, Zhuang QY: Rapamycin regulates Akt and ERK phosphorylation through mTORC1 and mTORC2 signaling pathways. Mol Carcinog 2010;49:603-610.

47 Petricoin EF, 3rd, Espina V, Araujo RP, Midura B, Yeung C, Wan X, Eichler GS, Johann DJ, Jr., Qualman S, Tsokos M, Krishnan K, Helman LJ, Liotta LA: Phosphoprotein pathway mapping: Akt/mammalian target of rapamycin activation is negatively associated with childhood rhabdomyosarcoma survival. Cancer Res 2007;67:3431-3440.

-48 Shi Y, Yan H, Frost P, Gera J, Lichtenstein A: Mammalian target of rapamycin inhibitors activate the AKT kinase in multiple myeloma cells by up-regulating the insulin-like growth factor receptor/insulin receptor substrate-1/phosphatidylinositol 3-kinase cascade. Mol Cancer Ther 2005;4:1533-1540.

49 Zhang W, Chen B, Zhang Y, Li K, Hao K, Jiang L, Mou X, Xu X, Wang Z: The anti-hepatocellular carcinoma cell activity by a novel mTOR kinase inhibitor CZ415. Biochem Biophys Res Commun 2017;10.1016/j. bbrc.2017.03.156

50 Li Y, Zhang J, Chen X, Liu T, He W, Chen Y, Zeng X: Molecular machinery of autophagy and its implication in cancer. Am J Med Sci 2012;343:155-161.

51 Janku F, McConkey DJ, Hong DS, Kurzrock R: Autophagy as a target for anticancer therapy. Nat Rev Clin Oncol 2011;8:528-539.

52 Klionsky DJ, Emr SD: Autophagy as a regulated pathway of cellular degradation. Science 2000;290:17171721.

-53 Din FV, Valanciute A, Houde VP, Zibrova D, Green KA, Sakamoto K, Alessi DR, Dunlop MG: Aspirin inhibits mTOR signaling, activates AMP-activated protein kinase, and induces autophagy in colorectal cancer cells. Gastroenterology 2012;142:1504-1515 e1503.

54 Kim J, Kundu M, Viollet B, Guan KL: AMPK and mTOR regulate autophagy through direct phosphorylation of Ulk1. Nat Cell Biol 2011;13:132-141.

55 Jung CH, Jun CB, Ro SH, Kim YM, Otto NM, Cao J, Kundu M, Kim DH: ULK-Atg13-FIP200 complexes mediate mTOR signaling to the autophagy machinery. Mol Biol Cell 2009;20:1992-2003.

56 Zheng B, Mao JH, Qian L, Zhu H, Gu DH, Pan XD, Yi F, Ji DM: Pre-clinical evaluation of AZD-2014, a novel mTORC1/2 dual inhibitor, against renal cell carcinoma. Cancer Lett 2015;357:468-475. 